\title{
Power Quality Improvement Using Dynamic Voltage Restorer for Various Line Faults
}

\author{
S. Balaji ${ }^{a}$, P. Jagannathan ${ }^{a}$, S. Jayapriya ${ }^{a}$, Ajay Krishna ${ }^{a}$ and R. Karthik ${ }^{b}$ \\ ${ }^{a}$ Final year Student, Dept. of Electrical and Electronics Engineering, SRM Valliammai Engineering college, Kattankulathur, \\ Tamilnadu, India. \\ ${ }^{\mathrm{b}}$ Associate Professor Dept. of Electrical and Electronics Engineering, SRM Valliammai Engineering college, Kattankulathur, \\ Tamilnadu, India.
}

Article History: Received: 11 January 2021; Accepted: 27 February 2021; Published online: 5 April 2021

\begin{abstract}
Electrical systems are subjected to a wide range of power quality problems which interrupt production processes. Equipment sensitivity may lead to downtime scrap and capacity losses. Also, good power quality saves more energy and money. One approach to address voltage sag problem is by implementing Dynamic Voltage Restorer (DVR) as it gives compensation to sag, swell, improves the line regulation and restores load voltage within a few milliseconds. DVR are a relatively new static VAR device that has seen applications in a variety of distribution and transmission applications. Due to its miniaturization, and cost reliability it includes fast dynamic response. This proposal presents modelling, analysis of voltage sags and correction of power factor for improved power quality using MATLAB/SIMULINK which includes as PI Controller and Discrete PWM generator for the control purpose of DVR
\end{abstract}

Keywords: DVR (Dynamic Voltage Restorer), Pulse width modulation (PWM), Power factor, Voltage sag.

\section{Introduction}

Power quality is the ability of electrical equipment to operate in a satisfactory manner. With ever-increasing use of sophisticated controls and equipment in industrial, commercial, institutional, and governmental facilities, the continuity, reliability and quality of electrical service has become extremely crucial to many power users. Over the past decade, the amount of electronic equipment such as PCs, process controllers, ASD has increased dramatically. As electronic equipment become more powerful and versatile, the potential for power problems also increased. This results rise in harmonics on power systems (Pedro, 2009; Bhasha, 2020). So any power issues exhibit in voltage, frequency, or current deviations that result in breakdown or disoperation of the consumer apparatus can be classified into power quality problem. In order to deliver pure and clean power i.e. pure sinusoidal voltage waveform, FACTS devices are used. Many FACTS devices are being used in electrical network, some of them are, Static Synchronous Series Compensator (SSSC), Static Synchronous Compensator (STATCOM), Unified Power Flow Controller (UPFC), Interline Power Flow Controller (IPFC) etc. In actual process FACTS apparatus were designed for the transmission system and it can be used in distribution system also, named as Custom Power Devices. Some commonly used Custom Power Devices are: Dynamic Voltage Restorer (DVR), Distribution Static Synchronous Compensator (DSTATCOM), and Active Filter (AF) etc. With the help of these devices the quality problems are improved to great extents (Nielsen,2005; ChinnamahammadBhasha, 2020). Due to its fast response, DVR is considered as one of the most effective and efficient power custom devices distribution systems has lots of power quality issues example, swell, sag, transients, etc. but voltage sag is the serious disorder which is mainly due to transients (ChinnamahammadBhasha, 2020; Deepthi, 2019). In order to check voltage sag and voltage swell in distribution system DVR is one of the effective and efficient custom power devices.

\subsection{The Working of the project}

DVR is a solid-state power electronics switching device consisting of either GTO or IGBT, a capacitor bank as a energy storage device and injection transformers (Anita Pakharia, 2012). The $230 \mathrm{~V}$, single phase supply is stepped down to $12 \mathrm{~V}$ by means of a step-down transformer and cascaded tapping transformers to meet the need. The incoming stepped down voltage waves comprises of harmonics. These harmonic components are filtered by means of an LC circuit comprising of a Toroid coil acting as an inductor and parallel Electrolytic capacitors. $5 \mathrm{~V}$ of the stepped down voltage is fed to the pic Microcontroller which generates the PWM signal for the DVR. The pic microcontroller is connected to the TLP250 Opto coupler driver circuit comprising of transistors and Zener diode which amplifies the 5V PWM pulses to $12 \mathrm{~V}$ for the MOSFET switch (Saikumar, 2016; Eashwaramma, 2018; Garikapati, 2020). During normal operating condition, the DVR injects only a small voltage to compensate for the voltage drop of the injection transformer and device losses. However, when voltage sag occurs in the distribution system, the DVR control system calculates and synthesizes the voltage required to maintain output voltage to the load by injecting a controlled voltage with a certain magnitude and phase angle into the distribution system to the critical load.The instantaneous power factor of the end load is displayed in a 16x2 LCD display (Kanwar, 2016; Rao,2016; Garikapati, 2021; Pavan, 2020).

\section{Literature survey}




\subsection{Existing System}

The present transmission system cannot be easily extended due to limited resources. Therefore, the expansion in transmission capacity is a viable solution. Transmission lines are not being fully utilized due to some limiting factors affecting the loading capability of the transmission line (Gandhi, 2017). These factors are perceived as the thermal limit, dielectric, and stability. FACTS controllers can control power and enhance the usable capacity of present lines. The FACTS controllers enable the power to flow through line under normal conditions and when subjected to faults and allow a line to transport power close to its thermal ratings.DVR is used on the distribution feeder to protect the load from faults due to the voltage sags and voltage swells. DVR is mounted in series with the load, and a battery energy storage system (BESS) is connected with a transformer and inverter are also connected with DVR, which compensate the active and reactive power requirement for the reduction in voltage sags and voltage swells. For the voltages stability, DVR injects voltage into the distribution system, the DVR to the system through the transformer (Nielsen, 2005; Arunkarthikeyan, 2020). DVR is the FACTS device, which compensates the disturbances like the voltage sags, swells, and voltages harmonics from the loads. DVR injects the voltages in series with the transmission lines and injects a small number of voltages in normal conditions (Arunkarthikeyan, 2021; Balamurugan, 2018). But, when a disturbance occurs, DVR calculates the voltages required to protect the load through the sinusoidal pulse width modulation (SPWM) (Laxmi, 2017). Then after those voltages are injected in the system to maintain the situation. In the steady-state, DVR either absorbs or delivers the active or reactive power, but when a disturbance occurs, DVR delivers or absorbed the active or reactive power from the dc-link.

\subsection{Proposed system}

The aim of this work is to design and implement a Power factor improvement circuit for various transmission line faults using high speed driver circuits that drives the DVR control units and periodic monitoring of power factor and to display the same.

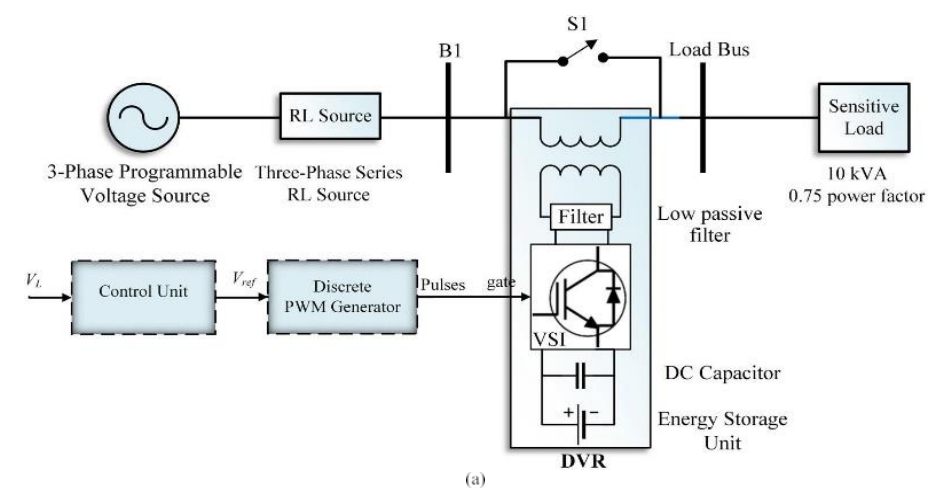

Figure 1. DVR Configuration

\subsection{Block diagram:}

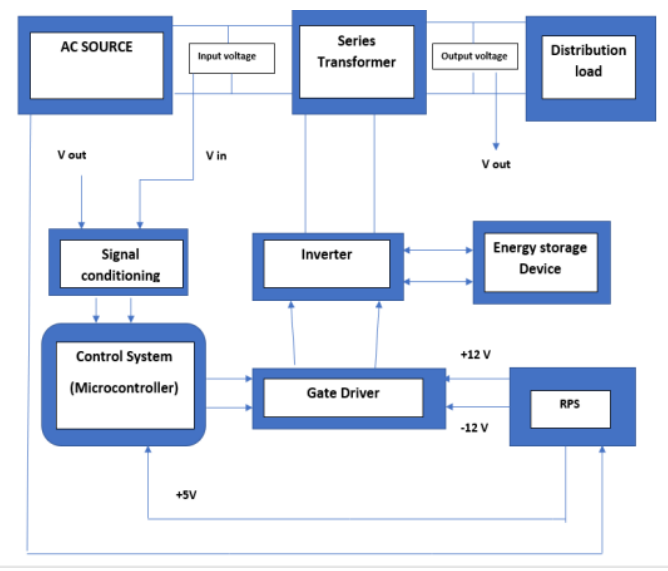

Figure 2. Overall Block Diagram of the model

\subsection{Hardware Used}

The elements of this work include: 
AC Source (Input source)

TLP250-Opto coupler Driver circuit

DSPIC30F2010- Microcontroller circuit

IRF840N-MOSFET

230-12 V Step down and tapping transformer

Toroid coil and Electrolytic capacitors (LC Circuit)

* 16 X 2 LCD Display

1) The AC source is the input supply acting as source 1 and if needed another AC supply from a solar source can be taken for to evaluate double line faults.

2) To power the pic microcontroller, $5 \mathrm{~V}$ from the stepped down voltage is fed to it. This MC board generates PWM signals for the single phase 180 degree conduction mode inverters having four MOSFET transistors in two legs.

3) The MC board powers the Optocoupler driver circuit comprising of Zener diode, and transistors which amplifies the $5 \mathrm{~V}$ to $12 \mathrm{~V}$ for energizing the Single-phase inverter circuit.

4) A MOSFET switch operate in 180 degree and does the necessary voltage sag compensation.

5) The $16 \times 2$ LCD display monitors and displays the power factor

\section{Simulation and Results}

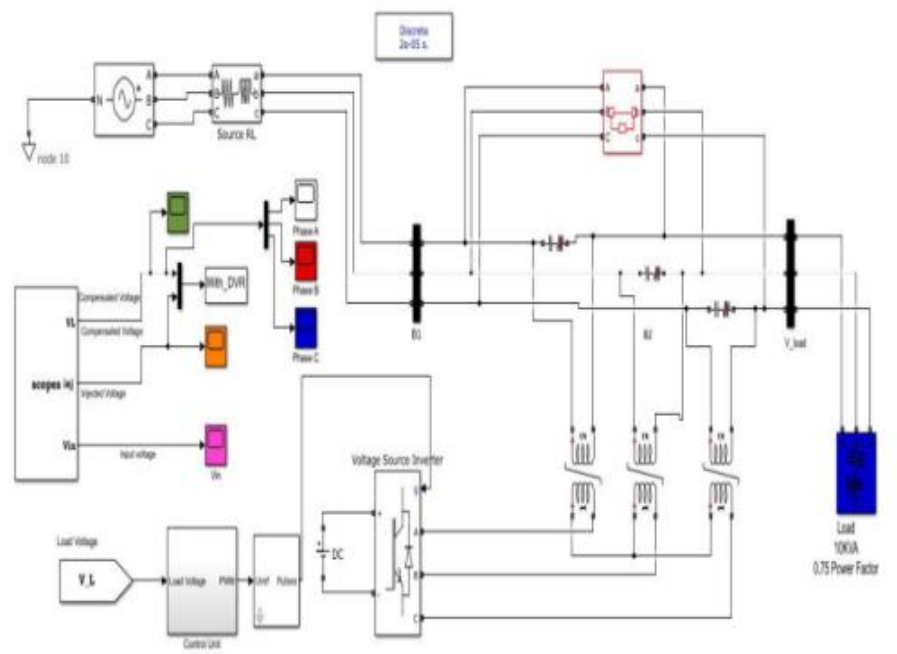

Figure 3. Simulation model of test system with DVR

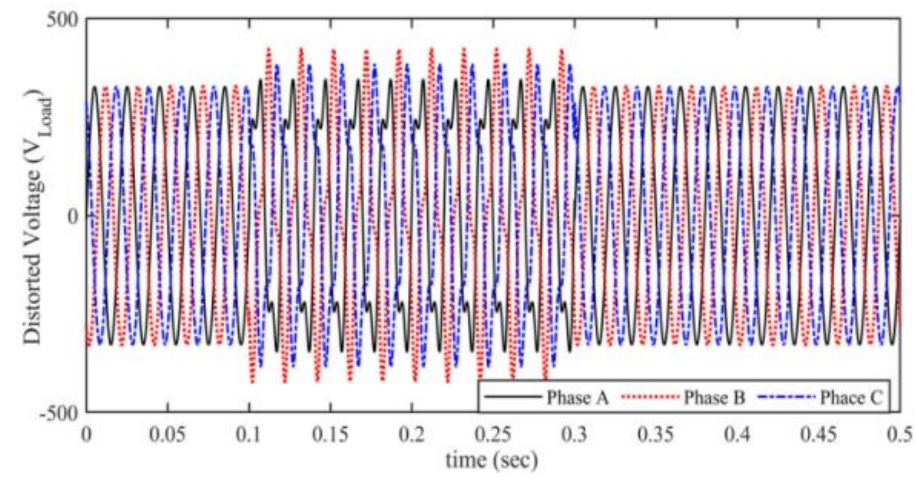

Figure 4. Distorted Load Voltage waveform before compensation 


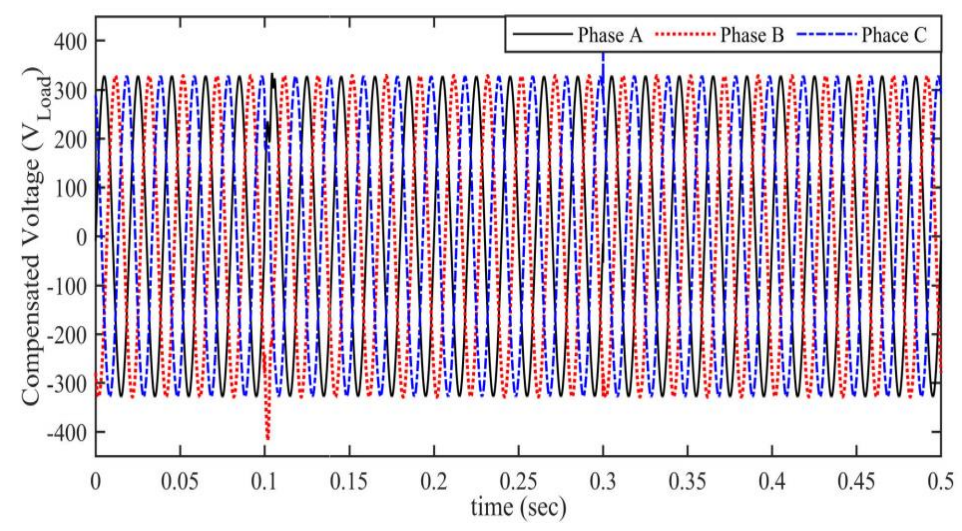

Figure 5. Compensated Load Voltage waveform in the system with DVR

\section{Advantages}

1. The proposed system provides the voltage regulation and harmonics reduction for various line faults

2. DVR with four leg inverters is used to protect sensitive electric load from power quality problems such as voltage sag, swell, unbalance and distortions.

The DVR can restore the load voltage within a few milliseconds and provides controllable voltage source.

\section{Conclusion}

DVR is proposed as the most note-worthy device to enhance the quality of power and proved to be a useful and well performing device. Through the platform of MATLAB/Simulink, a simulation of DVR with a power circuit is carried out by structuring and modelling of the control circuit and power system with a sensitive load. The DVR is implemented with the test system and investigated with and without DVR.

\section{References}

1. Anita Pakharia, Manoj Gupta (2012) Dynamic Voltage Restorer for compensation of voltage sag and swell,||, IJAET, ISSN: 2231-1963,. 4 :p.p. 347-355.

2. Arunkarthikeyan K., and Balamurugan K. (2021) Experimental Studies on Deep Cryo Treated Plus Tempered Tungsten Carbide Inserts in Turning Operation. In: Arockiarajan A., Duraiselvam M., Raju R. (eds) Advances in Industrial Automation and Smart Manufacturing. Lecture Notes in Mechanical Engineering. Springer, Singapore. https://doi.org/10.1007/978-981-15-4739-3_26

3. Arunkarthikeyan, K. and Balamurugan, K., (2020) July. Performance improvement of Cryo treated insert on turning studies of AISI 1018 steel using Multi objective optimization. In 2020 International Conference on Computational Intelligence for Smart Power System and Sustainable Energy (CISPSSE) (pp. 1-4). IEEE.

4. Balamurugan K, Uthayakumar M, Sankar S, Hareesh US, Warrier KG. (2018) Preparation, characterisation and machining of LaPO4-Y2O3 composite by abrasive water jet machine. International Journal of Computer Aided Engineering and Technology, 10(6), pp.684-697.

5. Bhasha, A.C., Balamurugan, K. (2020) End mill studies on Al6061 hybrid composite prepared by ultrasonic-assisted stir casting. Multiscale and Multidiscip. Model. Exp. and Design, https://doi.org/10.1007/s41939-020-00083-1

6. ChinnamahammadBhasha, A., Balamurugan, K. (2020) Studies on Al6061nanohybrid Composites Reinforced with $\mathrm{SiO} 2 / 3 x \%$ of TiC -a Agro-Waste. Silico,. https://doi.org/10.1007/s12633-020-00758-x

7. Chinnamahammad Bhasha and Balamurugan K, (2020) Multi-objective optimization of high-speed end milling on Al6061/3\% RHA/ 6\% TiC reinforced hybrid composite using Taguchi coupled GRA, International Conference on Computational Intelligence for Smart Power System and Sustainable Energy (CISPSSE), Keonjhar, India, 2020, pp. 1-6, doi: 10.1109/CISPSSE49931.2020.9212295.

8. Deepthi T, and Balamurugan K. (2019) Effect of Yttrium (20\%) doping on mechanical properties of rare earth nano lanthanum phosphate (LaPO4) synthesized by aqueous sol-gel process. Ceramics International. 45(15), pp.18229-18235.

9. Eashwaramma, N., J. Praveen, And M. Vijayakumar (2018)"Reduced Number Of Power Switches In Multi Level Inverter Using Spwm Technique To Mitigate For Sag And Swell." International Journal of Applied Engineering Research and Development (IJAERD) $8.1: 1-10$ 
10. Garikipati P, and Balamurugan K. (2021) Abrasive Water Jet Machining Studies on AlSi 7+ 63\% SiC Hybrid Composite. InAdvances in Industrial Automation and Smart Manufacturing, pp. 743-751, Springer, Singapore.

11. Gandhi, ronak, gajendra patel, and harshkumar sharma (2017) simulation of distributed power flow controller facts device in voltage sag and swell mitigation." International Journal of Electrical and Electronics Engineering Research (IJEEER) 7.2 : 39-44

12. Garikapati P, Balamurugan K, Latchoumi TP, Malkapuram R. (2020) A Cluster-Profile Comparative Study on Machining AlSi 7/63\% of SiC Hybrid Composite Using Agglomerative Hierarchical Clustering and K-Means. Silicon. https://doi.org/10.1007/s12633-020-00447-9

13. Kanwar, Paramjit Singh, And Rk Sharma.(2016) "Power Quality And Voltage Stability Of Transmission Line Using Statcom And Sssc." International Journal of Electrical and Electronics Engineering (IJEEE) $5,4: 1-8$

14. Laxmi, S. Vijaya, and Pv Ramana Rao (2017) Super Conducting Magnetic Energy System With Dvr For Voltage Quality Improvement Using Pso Based Simple Abc Frame Theory." International Journal of Electrical and Electronics Engineering Research (IJEEER) 7.2 : 1-10

15. Nielsen, J.G., Blaabjerg, F. (2005) a detailed compatrison of system topologies for dynamic voltage restorers,||, IEEE Trans. IND.APPL., 41, (5)pp.1272-1280.

16. Pedro Roncero-samchez- (2009) a veraile control scheme for a dynamic voltage restorer for power quality imptovement || IEEE transactions on power delivery,24(1), pp 277-284.

17. Rao, D. Rama Chadra, Et Al (2016)"Enhancement Of Power Quality Using Mc-Dpfc In Transmission System." International Journal of Electrical and Electronics Engineering Research (IJEEER) 6.6 : 1 -12

18. Saikumar, Karthik.(2016) "Design And Development Of Permanent Magnet Synchronous Generator (Pmsg) Based On Svpwm Techniques Using Wind Energy System." International Journal of Electrical and Electronics Engineering Research (IJEEER) $6.2: 1-12$ 